\title{
EQUILIBRIUM STUDIES OF 2,2'-(5-BROMO-6-METHYLPYRIMIDINE-2,4-DIYL)BIS(AZANEDIYL) DIPROPANOIC ACID WITH SOME TRANSITION-METAL IONS IN AQUEOUS SOLUTION
}

\author{
Seyed A. A. Sajadia,*, Ghodsieh Bagherzadeh ${ }^{\mathrm{b}}$, Marzieh Khaleghian ${ }^{\mathrm{a}}$, Maryam Mirbagheri ${ }^{\mathrm{a}}$ and Hosein Safaie $^{\mathrm{b}}$ \\ anstitute of Water \& Energy, Sharif University of Technology, P.O.Box 11155-8639 Tehran, Iran \\ ${ }^{b}$ Departement of Chemistry, Birjand University, Birjand, Iran
}

Recebido em 17/07/2013; aceito em 26/01/2014; publicado na web em 10/04/2014

\begin{abstract}
The stability constants of the 1:1 complexes formed between $\mathrm{M}^{2+}\left(\mathrm{M}^{2+}: \mathrm{Mn}^{2+}, \mathrm{Ni}^{2+}, \mathrm{Cu}^{2+}\right.$, or $\left.\mathrm{Cd}^{2+}\right)$ and $\mathrm{BMADA}^{2-}\left(\mathrm{BMADA}^{2}\right.$ 2,2'-(5-bromo-6-methylpyrimidine-2,4 diyl)bis(azanediyl)dipropanoic acid) were determined by potentiometric $\mathrm{pH}$ titration in aqueous solution $\left(I=0.1 \mathrm{~mol} \mathrm{~L}^{-1}, \mathrm{NaNO}_{3}, 25^{\circ} \mathrm{C}\right)$. The stability of the binary M-BMADA complexes is determined by the basicity of the carboxyl or amino groups. All the stability constants reported in this work exhibit the usual trend, and the order obtained was $\mathrm{Mn}^{2+}<\mathrm{Ni}^{2+}<\mathrm{Cu}^{2+}>\mathrm{Cd}^{2+}$. The observed stability order for BMADA approximately follows the Irving-Williams sequence. In the M-BMADA complexes, the $\mathrm{M}$ ion is able to form a macrochelate via the pyrimidine group of BMADA.
\end{abstract}

Keywords: divalent metal ions; potentiometric titration; acidity and stability constants.

\section{INTRODUCTION}

The properties of $N, N$-ethylenediamino diacetic acid (EDDA) and its derivatives have been well known, and extensive studies of the equilibria between EDDA and transition-metal ions have been reported by several researchers. ${ }^{1}$ Although there has been considerable speculation about the reason for this unusually strong affinity of EDDA, especially with the metal ions, additional quantitative data have been obtained. The EDDA anion has been considered to bond as a tetradentate ligand to metal ions; however, various researchers have disagreed on the probable structures of the corresponding chelates. ${ }^{2}$

In this study, to obtain additional information on the relationship between ligand structure and chelation, the metal stability constants of two amino acids that are structurally related to EDDA have been measured. Both EDDA and 2,2' -(5-bromo-6-methylpyrimidine-2,4diyl)bis(azanediyl)dipropanoic acid (BMADA) have two nitrogen atoms and two acetate groups, but they differ from each other due to the additional substituents on their nitrogen atoms. Note that complex formation involving EDDA results in the formation of five-membered chelate rings.

The $\alpha$-amino and $\alpha$-carboxyl groups of amino acids play a prominent role in metal-ion binding. ${ }^{3-9}$ The literature contains numerous examples of side-chain functional groups that also interact with metal ions. Based on the abovementioned essential role of amino acids, the interaction between other metal ions and BMADA is an interesting topic of study (Figure 1). Because of the essential role of amino acids in biological systems, their interactions and ability to form complexes with different metal ions needs to be investigated. In this study, because of the structural similarity of amino acids and BMADA, we expect the behavior of BMADA to be behavior similar to that of amino acids, e.g., BMADA has a carboxyl group that can coordinate with metal ions. Unlike amino acids, which contain primary amine groups, BMADA contains a secondary amine group. Note that secondary amine groups are normally sterically inhibited, which prevents their coordination with other groups. However, in the case of BMADA, a metal ion can simultaneously coordinate to both the carboxyl group and to the

*e-mail: sajadi@sharif.ac.ir<smiles>Cc1nc(NC(C)C(=O)O)nc(NC(C)C(=O)O)c1Br</smiles>

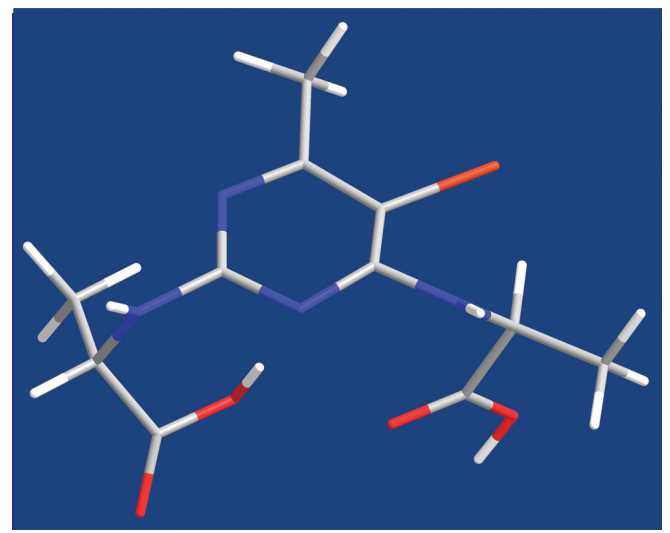

Figure 1. Chemical structure of BMADA

amino group, leading to the formation of a macrochelate.

\section{EXPERIMENTAL}

\section{Materials}

The nitrate salt of $\mathrm{Na}^{+}, \mathrm{Mn}^{2+}, \mathrm{Ni}^{2+}, \mathrm{Cu}^{2+}$, and $\mathrm{Cd}^{2+}$ (all pro analysis) were purchased from Merck, Darmstadt, Germany. BMADA was synthesized by G. Bagherzadeh according to published procedures. ${ }^{10}$ The purification of BMADA was carefully performed and the yield was ca. $98 \%$. All the starting materials were of pro analysis grade and were used without further purification. Potassium hydrogen phthalate, standard solutions of sodium hydroxide (titrasol), nitric acid, and EDTA as well as standard buffer solutions of $\mathrm{pH} 4.0,7.0$, and 9.0 were all purchased from Merck. All solutions were prepared with deionized water. The water was purified by a Milli-Q water purification system, deionized, and distilled. 


\section{pH titrations}

Reagents

Carbonate-free sodium hydroxide $\left(0.03 \mathrm{~mol} \mathrm{~L}^{-1}\right)$ was prepared and standardized against sodium hydrogen phthalate and a standard solution of $0.5 \mathrm{mmol} \mathrm{L}^{-1}$ nitric acid. M(II) nitrate solutions $(0.03 \mathrm{~mol}$ $\mathrm{L}^{-1}$ ) were prepared by dissolving the abovementioned metal nitrates in water and were standardized against a standard solution of 0.1 mol L ${ }^{-1}$ EDTA (triplex).

Apparatus

All pH titrations were performed using a Metrohm 794 basic automatic titrator (Titrino) coupled to a Hero thermostated bath at 25 ${ }^{\circ} \mathrm{C}\left( \pm 0.1{ }^{\circ} \mathrm{C}\right)$ and a Metrohm combined glass electrode $(\mathrm{Ag} / \mathrm{AgCl})$. The $\mathrm{pH}$ meter was calibrated using standard buffer solutions ( $\mathrm{pH} 4.0$, 7.0, and 9.0) obtained from Merck.

\section{Procedure}

To determine the acid dissociation constants of BMADA, an aqueous solution $\left(0.3 \mathrm{mmol} \mathrm{L}^{-1}\right)$ of the protonated ligand was titrated with $0.03 \mathrm{~mol} \mathrm{~L}^{-1} \mathrm{NaOH}$ at $25^{\circ} \mathrm{C}$ under a nitrogen atmosphere and at an ionic strength of $0.1 \mathrm{~mol} \mathrm{~L}^{-1}, \mathrm{NaNO}_{3}$. For the determination of binary (a ligand and $\mathrm{M}^{2+}$ ) systems, the ratios used were 1:1, M(II): BMADA, $0.3 \mathrm{mmol} \mathrm{L}^{-1}$. This solution was titrated with $0.03 \mathrm{~mol}$ $\mathrm{L}^{-1} \mathrm{NaOH}$ under the same conditions previously mentioned. Each titration was repeated seven times to verify the reproducibility of the data.

\section{Calculations}

The acid dissociation constants, i.e., $K_{H_{2}(B M A D A)}^{H}, K_{H(B M A D A)}^{H}$, and $K_{B M A D A}^{H}$ for $\mathrm{H}_{2}$ (BMADA) were calculated using an algebraic method. ${ }^{11,12}$ The equilibrium involved in the formation of a given 1:1 complex of BMADA and a divalent metal ion can be expressed as equilibria (1) and (2). The stability constants $K_{M(B M A D A)}^{M}$ for the $\mathrm{M}^{2+}$ metal-ion complexes were calculated using a computer connected to a printer for each pair of titrations by considering the following species: $\mathrm{H}^{+}, \mathrm{H}_{2}$ (BMADA), H(BMADA) ${ }^{-}, \mathrm{BMADA}^{2-}, \mathrm{M}^{2+}$, and M(BMADA). Throughout the analyses, the data were collected every $0.1 \mathrm{pH}$ unit from ca. $10 \%$ complex formation to ca. $90 \%$ degree of neutralization or to the beginning of the hydrolysis of $\mathrm{M}_{(\mathrm{aq})}{ }^{2+}$, which was evident from the titration performed in the absence of BMADA. The values calculated individually for $K_{M(B M A D A)}^{M}$ showed no dependence on $\mathrm{pH}$ or on the amount of excess $\mathrm{M}^{2+}$.

\section{RESULTS AND DISCUSSION}

The potentiometric $\mathrm{pH}$ titrations $\left(25^{\circ} \mathrm{C}, 0.1 \mathrm{~mol} \mathrm{~L}-1, \mathrm{NaNO}_{3}\right)$ were performed to obtain the acidity and stability constants, which are summarized in Tables 1 and 2.

Table 1. Negative logarithm of the acidity constants of $\mathrm{H}_{2}(\mathrm{BMADA})$ at $25^{\circ} \mathrm{C}$, $0.1 \mathrm{~mol} \mathrm{~L}^{-1}, \mathrm{NaNO}_{3}$, eqs.(1) and (2)

\begin{tabular}{ccc}
\hline No. & Species & $\mathrm{pKa}^{*}$ \\
\hline 1 & $\mathrm{H}_{2}$ (BMADA) & $4.09 \pm 0.03$ \\
2 & H(BMADA) & $7.05 \pm 0.02$ \\
3 & BMADA & $9.86 \pm 0.04$ \\
\hline
\end{tabular}

*The given errors are three times the standard error of the mean value or the sum of the propagable systematic errors.
Table 2. Logarithm of the stability constants of binary complexes of $\mathrm{M}^{2+}$ at $25^{\circ} \mathrm{C}, 0.1 \mathrm{~mol} \mathrm{~L}^{-1}, \mathrm{NaNO}_{3}^{*}$, eq. (4)

\begin{tabular}{ccc}
\hline No. & Species & $\log K_{M(T p)}^{M}$ \\
\hline 1 & $\mathrm{Mn}^{2+}$ & $4.72 \pm 0.05$ \\
2 & $\mathrm{Ni}^{2+}$ & $5.76 \pm 0.06$ \\
3 & $\mathrm{Cu}^{2+}$ & $6.35 \pm 0.05$ \\
4 & $\mathrm{Cd}^{2+}$ & $5.98 \pm 0.08$
\end{tabular}

*The given errors are three times the standard error of the mean value or the sum of the propagable systematic errors.

\section{Acidity constants}

BMADA ion $\left(\mathrm{BMADA}^{2-}\right), \mathrm{R}\left(\mathrm{NHCH}\left(\mathrm{CH}_{3}\right) \mathrm{CO}_{2}\right)_{2}{ }_{2}^{2-}$, is a dibasic species; thus, it can accept two protons at the carboxyl site. However, $\mathrm{BMADA}^{2-}$ releases another proton from its amine group, for which the following deprotonation equilibria hold:

$\mathrm{H}_{2}(\mathrm{BMADA})=\mathrm{H}^{+}+\mathrm{H}(\mathrm{BMADA})^{-}$

$K_{H_{2}(B M A D A)}^{H}=\left[\mathrm{H}\left(\mathrm{BMADA}^{-}\right]\left[\mathrm{H}^{+}\right] /\left[\mathrm{H}_{2}(\mathrm{BMADA})\right]\right.$

$\mathrm{H}(\mathrm{BMADA})^{-} \rightleftharpoons \mathrm{H}^{+}+\mathrm{BMADA}^{2-}$

$K_{H(B M A D A)}^{H}=\left[\mathrm{BMADA}^{2-}\right]\left[\mathrm{H}^{+}\right] /\left[\mathrm{H}\left(\mathrm{BMADA}^{-}\right]\right.$

BMADA $^{2-} \rightleftharpoons \mathrm{H}^{+}+\mathrm{BMADA}^{3-}$

$K_{B M A D A}^{H}=\left[\mathrm{BMADA}^{3-}\right]\left[\mathrm{H}^{+}\right] /\left[\mathrm{BMADA}^{H} \mathrm{H}^{2-}\right]$

Note that the two protons in $\mathrm{H}_{2}$ (BMADA) are released from $\mathrm{R}\left(\mathrm{NHCH}\left(\mathrm{CH}_{3}\right) \mathrm{CO}_{2} \mathrm{H}\right)_{2}$ according to equilibria (1) and (2). Its acetate groups do not undergo deprotonation, which occurs at the terminal acetate groups of related amino acids. ${ }^{11,12}$ Note that BMADA can release its first proton from the terminal acetate group; hence, here, equilibrium (1) should be considered, which occurs at ca. $\mathrm{pH} 4$ (Table 1). According to Table 1 and equilibrium (3), the third proton can be released from the amino group, $-\mathrm{NH}-$, at $\mathrm{pH} 9.86$.

\section{Stability of binary and ternary complexes}

If we abbreviate $\mathrm{Mn}^{2+}, \mathrm{Ni}^{2+}, \mathrm{Cu}^{2+}$, and $\mathrm{Cd}^{2+}$ as $\mathrm{M}^{2+}$ for simplicity, then we can write the following equilibria (4) and (5):

$\mathrm{M}^{2+}+\mathrm{H}(\mathrm{BMADA})^{-} \rightleftharpoons \mathrm{M}(\mathrm{H} ; \mathrm{BMADA})^{+}$

$K_{M(H ; B M A D A)}^{M}=\left[\mathrm{M}(\mathrm{H} ; \mathrm{BMADA})^{+}\right] /\left[\mathrm{M}^{2+}\right]\left[\mathrm{H}(\mathrm{BMADA})^{-}\right]$

$\mathrm{M}^{2+}+(\mathrm{BMADA})^{2-} \rightleftharpoons \mathrm{M}(\mathrm{BMADA})$

$K_{M(B M A D A)}^{M}=[\mathrm{M}(\mathrm{BMADA})] /\left[\mathrm{M}^{2+}\right]\left[\mathrm{BMADA}^{2-}\right]$

The collection of the experimental data associated with the potentiometric $\mathrm{pH}$ titrations can be completed by considering the abovementioned equilibria (1)-(5) if the titrations are not performed in the $\mathrm{pH}$ range, where the formation of a hydroxo complex occurs.

\section{Potentiometric analyses}

The results of all potentiometric $\mathrm{pH}$ titrations, i.e., the acidity and stability constants, are summarized in Tables 1 and 2 . The deprotonated $\mathrm{BMADA}^{2-}$ can accept two protons to afford the acid $\mathrm{H}_{2}$ (BMADA). When the first proton of these two protons, which is associated with a carboxylate residue, is released, its pKa is ca. 4. However, BMADA ${ }^{-}$can also release an additional proton at ca. $\mathrm{pH} 7$. The third proton is released from the amino group at ca. $\mathrm{pH}=9.86$, which is in agreement with similar derivatives of EDDA. ${ }^{11}$ 
The first acid dissociation constants determined in this study are in good agreement with the values reported by other authors for related amino acids. ${ }^{11,13,14}$ However, the carboxyl group is a far stronger acid than the residue group..$^{15}$

The stability constants of the binary complexes of M-BMADA were refined separately using the titration data of this system in a 1:1 ligand: $\mathrm{M}^{2+}$ ratio under the same conditions of temperature and ionic strength (according to equilibria 4 and 5) because they were not in agreement with the reported values for related amino acids, ${ }^{11,14}$ however, we did not achieve reasonable results for $K_{M(H: B M A D A)}^{M}$. All the stability constants in Table 2 approximately exhibit the usual trend, and the order obtained was $\mathrm{Mn}^{2+}<\mathrm{Ni}^{2+}<\mathrm{Cu}^{2+}>\mathrm{Cd}^{2+}$. The observed stability order for BMADA approximately follows the Irving-Williams sequence ${ }^{16}$ (Figure 2). According to the HSAB principle, hard acids prefer to coordinate to hard bases, and soft acids prefer to coordinate soft bases. Therefore, as per the principle, metal ions such as $\mathrm{Mn}^{2+}$ prefer to coordinate to carboxyl sites, and the other abovementioned metal ions (Table 2) (as borderline metal ions) tend to coordinate as bidentate ligands to both carboxyl groups and pyrimidine groups. ${ }^{17}$

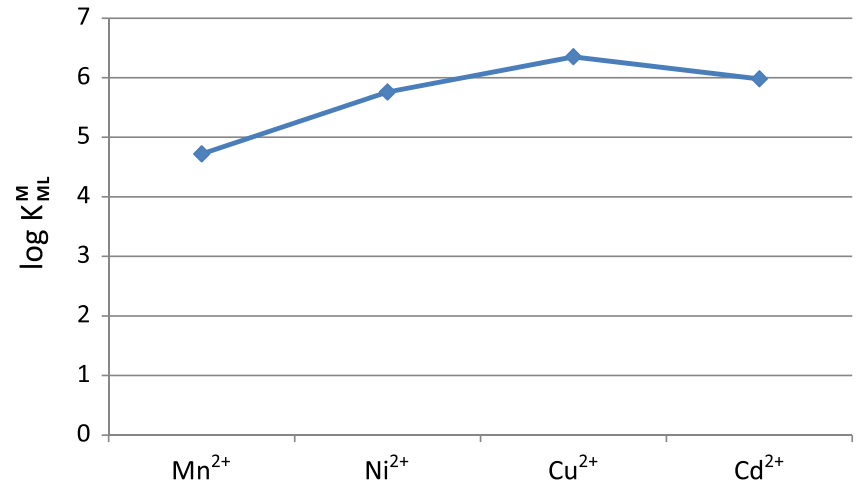

Figure 2. Irving-Williams sequence-type plot for the 1:1 complexes of $\mathrm{Mn}^{2+}$ and $C d^{2+}$ with BMADA (see Table 2)

If we compare the experimental stability constants determined from the potentiometric titrations of EDDA with BMADA (in this study) for some transition-metal ions (i.e., $\mathrm{Cu}^{2+}$ : $16.2,6.35$; $\mathrm{Ni}^{2+}$ : $13.5,5.76$; $\left.\mathrm{Cd}^{2+}: 8.8,5.98\right)$, we can easily determine that BMADA cannot coordinate as a tetradentate ligand with a single metal ion. Because BMADA is sterically inhibited, a metal ion such as $\mathrm{Cu}^{2+}$ cannot coordinate simultaneously to both amine groups on one side and to two carboxyl groups on the other side. Consequently, BMADA is considered to form less stable complexes compared to those formed with EDDA.

The result obtained is not surprising because the EDDA: $\mathrm{Cu}^{2+}$ complex has a square-planar arrangement of donor groups around the copper atom. Because only four coordination sites are required, the chelation of copper with both ligands probably involves the nitrogen atoms and the acetate groups; thus, the resulting EDDA: $\mathrm{Cu}^{2+}$ and $\mathrm{Cu}-\mathrm{BMADA}$ chelate structures would be similar.

Next, we report the successive acid dissociation constants of EDDA and BMADA and the stability constants of the 1:1 chelates. Comparing the chelation of the EDDA with various abovementioned divalent metal ions indicates that replacement of the acetate groups of EDDA with propionate groups results in a decrease in $\log \mathrm{K}$ by approximately three units.

We propose that the relatively strong tendency for dissociation of the first proton of these dibasic acids and the extremely low acidity of the second proton indicates interaction of the two tertiary amino nitrogen atoms to form a hydrogen bond. This is similar to the interaction already described by other authors ${ }^{11,18-20}$ for the corresponding acetic acid derivatives.

Amino acids contain a primary amine group, but BMADA contains a secondary amine group. As evident from the results, the acid dissociation constants of the second proton of amino acids and BMADA differ by approximately four log units. ${ }^{11,18}$ Moreover, the stability constants of amino acids and BMADA also differ substantially. In a previous study, amino acids have been demonstrated to simultaneously bond to metal ions as bidentate ligands (via their carboxyl and amine groups), which then leads to greater stability. However, in the case of BMADA, metal ions coordinate to the carboxyl group and to the pyrimidine ring, which also results in increased stability (Figure $3)$. Figure 3 shows that a $\mathrm{Cu}(\mathrm{II})$ ion is coordinated as a tridentate ligand to BMADA via the two carboxylate groups on one side and via $\mathrm{N}(3)$ of the pyrimidine ring on the other side.

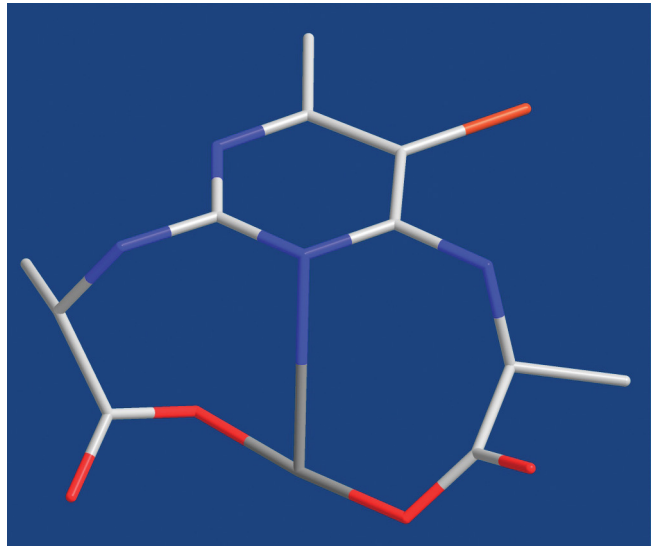

Figure 3. Schematic illustrations of the species with interactions according to equilibrium (5) for Cu(BMADA). The structure was drawn using the program CS Chem 3D, version 3.5, from CambridgeSoft Corporation

\section{REFERENCES}

1. Chabereck, S.; Martel, A.E.; J. Am. Chem. Soc. 1950, 72, 5357.

2. Celenza, J. L.; Curr. Opin. Plant Biol. 2001, 4, 34; Chabereck, S.; Martel, A. E.; J. Am. Chem. Soc. 1952, 74, 6228.

3. IUPAC-IUBMB Joint Commission on Biochemical Nomenclature. Nomenclature and Symbolism for Amino Acids and Peptides. Recommendations on Organic \& Biochemical Nomenclature, Symbols \& Terminology etc. Retrieved on 2007-05-17.

4. Foster, R.; Charge Transfer Complexes; Academic Press, New York: 1969.

5. Morita, F.; Biophys. Acta 1974, 343, 674.

6. Lehninger's Principles of Biochemistry ( $3^{r d}$ ed.); Nelson, D. L.; Cox, M. M., eds.; Worth Publishing: New York, 2000.

7. Stryer, L.; Biochemistry, $4^{\text {th }}$ ed., W.H. Freeman and Company: New York, 1995.

8. http://www.anyvitamins.com/millenium2000.htm, accessed June 2013.

9. http://www.evitamins.com/healthnotes.asp?ContentID $=1025008$, accessed June 2013.

10. Bakavoli, M.; Bagherzadeh, G.; Rahimizadeh, M.; Mendeleev Commun. 2005, 15, 145.

11. Martel, A. E.; Critical Stability Constants of Metal Complexes; Plenum Press: New York, 2006, p. 26; Chabereck, S.; Martel, A. E.; J. Am. Chem. Soc. 1953, 75, 4814.

12. Sajadi, S. A. A.; Alamolhoda, A. A.; Nazari Alavi, A.; Sci. Iran. 2013 in press; Taqui Khan, M. M.; Martel, A. E.; J. Am. Chem. Soc. 1967, 89, 5585; Sigel, H.; Zuberbueler, A. D.; Anal. Chim. Acta 1991, 255, 63; Sigel, H.; Massoud, S. S.; Corfu, N. A.; J. Am. Chem. Soc. 1994, 116, 2958; Sigel, R. K. O.; Song, B.; Sigel, H.; J. Am. Chem. Soc. 1997, 119, 
744; Sigel, H.; Chen, D.; Gregan, F.; Helv. Chim. Acta 1992, 75, 2634; Frey, C. M.; Stuehr, J. E.; J. Am. Chem. Soc. 1972, 94, 8898; Sigel, H.; Inorg. Nucl. Chem. 1977, 39, 1903; Kiss, T.; Soago, I.; Martin, R. B.; J. Am. Chem. Soc. 1989, 111, 3611.

13. Weast, R.C.; Handbook of Chemistry \& Physics, $55^{\text {th }}$ ed., CRC Press, Ohio: 1975, p. 129.

14. Pettit, L. D.; IUPAC Stability Conatants Database, Release 3, version 3.02; Academic Software Timble, UK, 1998.
15. Sigel, H.; Zuberbuehler, A. D.; Yamauchi, O.; Anal. Chim. Acta 1991, $255,63$.

16. Irving, H.; Williams, R. J. P.; J. Chem. Soc. 1953, 3192.

17. Sigel, H.; Naumann, C. F.; J. Am. Chem. Soc. 1976, 98, 730.

18. Courtney, R. C.; Chaberek Jr., S.; Martell, A. E.; J. Am. Chem. Soc. 1953, 75, 4814

19. Martell, A. E.; Chaberek Jr., S.; J. Am. Chem. Soc. 1950, 72, 5357.

20. Degischer, G.; Nancollas, G. H.; Inorg. Chem. 1970, 9, 1259. 